\title{
Rio, Cidade Inteligente? \\ Mobilidade de políticas e políticas de mobilidade no contexto dos megaeventos
}

\author{
Bianca Freire-Medeiros ${ }^{63}$ \\ João Freitas ${ }^{64}$
}

\section{Resumo}

Em paralelo ao urbanismo olímpico, um outro qualificativo de circulação global, igualmente complexo, porém menos discutido pelas ciências sociais brasileiras, emprestou legitimidade ao modelo de gestão urbana que se consolidou no Rio de Janeiro durante o ciclo dos megaeventos. 0 qualificativo a que nos referimos é o de "cidade inteligente" - tradução não literal de smart city. Nosso objetivo é examinar: a) sua inserção no fenômeno de "mobilidades de políticas", que pressupõe tanto o fluxo global de ideias, técnicas e práticas encarnadas por políticos, lobistas, empresários etc., quanto a circulação de modelos supostamente eficientes a serem não apenas replicados, mas adaptados e ressignificados em cada localidade; b) suas premissas discursivas e orientações práticas que, apresentadas como politicamente neutras, legitimaram o emprego de sistemas tecnológicos de controle e monitoramento capazes de alterar as "políticas de mobilidade", acirrando a desigualdade entre regimes de circulação em disputa na metrópole do Rio de Janeiro.

\section{Palavras-chave}

Mobilidades. Fluxos. Rio de Janeiro. Cidade inteligente.

\begin{abstract}
Parallel to the "Olympic urbanism", another equally complex phrase - but less discussed by the Brazilian social sciences - gave legitimacy to the urban management model that was consolidated in Rio de Janeiro during the mega-events cycle. The phrase we refer to is "smart city". We aim to examine: a) its insertion in the phenomenon of "politicy mobilities", which presupposes both the global flow of ideas, techniques and practices embodied by politicians, lobbyists, entrepreneurs, etc., as well as the circulation of supposedly efficient models that will not only be replicated but locally adapted and reframed; b) its discursive assumptions and practical orientations which,
\end{abstract}

${ }^{63}$ Professora do Departamento e do Programa de Pós-graduação em Sociologia da Universidade de São Paulo (USP). E-mail: bfreiremedeiros@gmail.com.

${ }^{64}$ Doutor e Mestre em História, Política e Bens Culturais pelo Centro de Pesquisa e Documentação de História Contemporânea do Brasil da Fundação Getúlio Vargas (CPDOC/FGV). E-mail: joaofreitas@id.uff.br 
presented as politically neutral, legitimized the use of technological control and monitoring systems capable of altering the "mobility policies", intensifying the inequality among competing regimes of circulation in the metropolis of Rio de Janeiro.

\section{Keywords}

Mobilities. Flows. Rio de Janeiro. Smart City.

\section{Introdução: a sede por ser cidade-sede}

A saga do Rio de Janeiro como cidade olímpica começou em 1995. A candidatura, visando à edição de 2004, previa concentrar as competições na Ilha do Fundão e a construção de um estádio, de uma Vila Olímpica e de um parque ecológico. Segundo Sérgio Rangel (2007), os delegados do Comitê Olímpico Internacional (COI), em visita de inspeção, teriam se espantado com o esgoto in natura sendo despejado na Baía de Guanabara. A questão da segurança era, por certo, um ponto ainda mais crítico. A boa impressão causada pela organização de outro megaevento - a Conferência das Nações Unidas sobre o Meio Ambiente e o Desenvolvimento (Eco-92), que reunira com razoável sucesso centenas de chefes de Estado, lideranças de movimentos sociais e jornalistas - havia sido borrada, no ano seguinte, pelas manchas de sangue da Chacina da Candelária, em que oito menores de idade foram assassinados. Essa primeira candidatura, como sabemos, não obteve êxito.

Uma nova candidatura foi lançada em 2003, visando aos Jogos Olímpicos de 2012. O então prefeito César Maia, eufórico por ter vencido a disputa local contra São Paulo, parafraseou a sentença - machista, que se frise - do poeta Vinicius de Moraes para exaltar o feito: "As feias que me perdoem, mas beleza é fundamental". Fundamental ou não, fato é que nem sua notória beleza bastou para que a Cidade Maravilhosa chegasse à fase final da disputa.

Foi, portanto, apenas na terceira candidatura que a capital fluminense logrou o resultado pretendido: em outubro de 2009, representantes dos três níveis de governo e uma população efusiva celebraram a vitória do projeto "Rio, Cidade Olímpica e Paralímpica 2016" - ápice de uma longa lista de megaeventos iniciada com os Jogos Pan-Americanos de 2007 e que incluía a Copa do Mundo FIFA 2014, além da Jornada Mundial da Juventude (2013), da Rio+20 (2012) e dos Jogos Mundiais Militares (2011). Como amplamente discutido (ver LIRA, 2010; MASCARENHAS et al., 2012; DAVIES, 2017), foram inúmeras as iniciativas legais (esforços diplomáticos em muitas instâncias de negociação) e ilegais (fraudes, 
subornos e lavagem de dinheiro ${ }^{65}$ ) que, em alinhamentos complexos, garantiram o convencimento a respeito da viabilidade do Rio como cidade-sede.

Muitos dos problemas urbanísticos que emperraram as candidaturas anteriores estavam - como hoje ainda estão - longe de ser resolvidos. Resta, portanto, examinar que inflexões práticas e discursivas operaram em diferentes escalas e permitiram o protagonismo do Rio de Janeiro no chamado ciclo dos megaeventos (ROCHA, 2017). Com essa lacuna em mente e atentos à proposta deste dossiê de situar os megaeventos na chave interpretativa dos modos de gestão do urbano, nosso objetivo é analisar o papel determinante, e ainda pouco examinado, que as premiadas ações de "urbanismo inteligente" 66 , acomodadas sob a alcunha de Rio Smart City, cumpriram na adaptação à realidade brasileira do modelo de urbanismo olímpico. O que ficou conhecido como Rio Smart City diz respeito, portanto, ao conjunto de esforços políticos e empresariais que fizeram com que a cidade fosse reconhecida como "cidade inteligente" 67 . Nossa análise toma como referência o período entre 2010 - quando o Centro de Operações Rio (COR) começa a ser gestado - e 2016, quando se encerra o segundo mandato do ex-prefeito Eduardo Paes. Se essa narrativa de "cidade inteligente", que foi concatenada em solo carioca, não chegou a vingar como se pretendia, fato é que deixou como legado - e esse é ponto principal que buscamos demonstrar - uma nova maneira de gerir a vida urbana largamente baseada tanto na fetichização de algoritmos e codificações, quanto na reificação do próprio imaginário da inteligência artificial apresentada como tecnicamente confiável e politicamente neutra.

Ainda que os limites deste artigo não comportem uma genealogia do projeto de "cidade inteligente", na próxima seção recuperamos, de forma breve e a partir do uso da noção de mobilidade de políticas, os caminhos percorridos por essa política de caráter transnacional até aportar no Rio de Janeiro. Fazendo uso do material empírico coletado com vistas à escrita da tese de doutorado intitulada "A invenção da cidade inteligente Rio: uma análise do Centro de Operações Rio

${ }^{65}$ Ver ALVES, R. et al. Cabral admite que comprou, por US\$ 2 milhões, votos para trazer a Olimpíada para o Rio. G1 Rio de Janeiro. Disponível em: https://g1.globo.com/rj/rio-dejaneiro/noticia/2019/07/04/sergio-cabral-depoe-sobre-compra-de-votos-para-o-rio-sediar-aolimpiada-de-2016.ghtml Acesso em: 08 out. 2019.

66 Entre os títulos que diferentes instituições internacionais conferiram ao Rio de Janeiro, cabe destacar o prêmio World Smart City conquistado pela gestão Eduardo Paes, em 2013, na cidade de Barcelona.

${ }^{67}$ Entre esses esforços, está elencado um projeto pontual que carrega o título Rio Smart City. Ele consistia na fixação de adesivos com QR Code em cinco mil pontos de ônibus com informações em português, inglês e espanhol sobre as linhas de transporte. Ainda que esse projeto específico seja parte do que aqui tratamos, nossas atenções não se detêm nele. 
pela lente das mobilidades (2010-2016)" (FREITAS, 2018), a seção 3 fecha o foco no COR para compreender como o emprego de seus sistemas tecnológicos de controle e monitoramento foram capazes de alterar as políticas de mobilidade (CRESSWELL, 2006; ADEY, 2010) na metrópole do Rio de Janeiro. Além das observações realizadas no COR e da análise de documentos oficiais, fazemos uso das entrevistas cedidas a um de nós pelo ex-prefeito Eduardo Paes em outubro de 2017, nos Estados Unidos, assim como por funcionários e ex-funcionários do COR, com os quais mantivemos o compromisso de anonimato. Nas considerações finais, trazemos algumas ponderações sobre as potencialidades e limites da proposta de urbanismo inteligente em termos mais gerais.

Vale dizer que a bússola analítica que utilizamos ao longo deste artigo é aquela forjada no contexto da chamada virada móvel que, nas últimas duas décadas, tem interpelado o sedentarismo epistêmico e metodológico característico da teoria social ${ }^{68}$. Estamos alinhados, sobretudo, com a chamada Escola de Lancaster em sua proposta de entendimento do mundo social como um entrelaçamento de movimento, representações e práticas socioespaciais, dependente tanto de infraestruturas materiais cada vez mais conectadas quanto da regulação de saberes, normas e protocolos cujas lógicas, não raro, escapam aos sujeitos leigos (cf. CRESSWELL, 2006; SHELLER; URRY, 2006, 2016; URRY 2000, 2007). Abordar as mobilidades não significa, portanto, ater-se somente ao fluxo de pessoas, objetos, ideias e informações, mas considerar também o movimento potencial, o movimento impedido e a imobilidade (BÜSCHER; URRY, 2009). Manderscheid (2009) reitera esse ponto:

As mobilidades e as desigualdades sociais estão entrelaçadas de modo complexo. Nem a mobilidade nem a desigualdade social são pré-definidas, estáticas ou categorias determinadas, mas ambos os conceitos são infundidos com significado, poder e compreensão contestada, ligados a práticas específicas e arranjos sociais e espaciais, continuamente reiterados e reproduzidos. (MANDERSCHEID, 2009, p.27. Tradução dos autores).

Trata-se, assim, de uma compreensão das mobilidades como um sistema complexo, ou variados sistemas interligados, sempre atravessados por jogos de poder: é nesse sentido que podemos falar em regimes de mobilidade que, amparados em dispositivos sociotécnicos de vigilância, definem o que e quem

${ }^{68}$ Para um panorama introdutório sobre o giro das mobilidades, ver Freire-Medeiros, Telles e Allis (2018). 
pode ou não circular (ADEY, 2010; SHELLER, 2018) - aqui incluídas as políticas urbanas. É o que veremos a seguir.

\section{A política de Smart City e sua mobilidade transnacional}

Como atestam inúmeros autores (MAHIZHNAN, 1999; HOLLANDS, 2008; GREENFIELD, 2013; DAMARI, 2013, entre outros), as smart cities despontaram em fins do século $X X$, simultaneamente à popularização da informática. Desde o início, o uso das Tecnologias de Informação e Comunicação (TICs) na gestão da cidade tem sido uma constante nos projetos e tentativas de definição do que é uma "cidade inteligente" (CARAGLIU; DEL BO; NUKAMP, 2009; DAMERI, 2013).

Hollands (2008) e Nam e Pardo (2011) registram a dificuldade de se encontrar algum conceito ou definição de cidade inteligente que seja amplamente reconhecido. Tal dificuldade é consequência das várias áreas que as iniciativas de smart cities podem compreender, por exemplo: E-Gov, construções sustentáveis/inteligentes, racionalização do uso da água e da energia elétrica, mobilidades urbanas digitalmente organizadas, educação e formação profissional com base em plataformas digitais, segurança pública baseada em monitoramento de câmeras operadas por inteligência artificial, entre outras.

Muitos dos projetos demonstram o que Kaika e Swyngedouw (2000) chamam de "fetichização da tecnologia", tratando tudo o que é "tecnológico" como a materialização do ideal de progresso. As TICs são apresentadas como soluções técnicas inequívocas, despolitizadas, utópicas e racionalistas, o que é reiterado pelo marketing congratulatório produzido pelas empresas envolvidas, reificando-se a visão da cidade inteligente como o único caminho possível para promover transformações urbanas.

O debate sobre smart cities não pode, obviamente, restringir-se à tecnologia. Novas implementações tecnológicas escalonam mudanças em outras dimensões da sociedade: para que tais tecnologias saiam dos laboratórios e dos key-notes dos executivos de grandes corporações e possam ser aplicadas ao mundo real, é necessária uma série de adaptações e comprometimentos sociais, institucionais e políticos. É fundamental considerar as práticas socioculturais das comunidades envolvidas e a adequação aos padrões legais e aos requisitos do planejamento local.

Não basta apenas desenvolver e empurrar as tecnologias para os usuários, as mudanças propostas pelos projetos de smart city têm uma natureza sociológica clara e desafiadora (CARVALHO, 2015). A sua rápida difusão tem se constituído 
como um fenômeno global e bastante heterogêneo, sendo possível observar projetos de cidades inteligentes de naturezas bastante distintas em desenvolvimento nos dois hemisférios. Nesse contexto, é importante mencionar a atuação extensiva das empresas de tecnologia como IBM, Cisco, Siemens, Microsoft, Huawei, Hitachi, Samsung, entre outras, que buscam proeminência em um mercado cujo valor cumulativo foi estimado em 1,565 trilhão de dólares para 2020 (VIDYASEKAR, 2013). São parcerias, consultorias, serviços de interpretação de metadados, planejamentos estratégicos, muitas vezes oferecidos às cidades sem custos explícitos: as empresas buscam espaços para testar suas tecnologias no tecido urbano e, aos poucos, constroem um portfólio de cidades que foram "salvas" por seus pacotes de soluções inteligentes. Hollands alerta sobre a participação das grandes corporações nesse mercado:

A sugestão de consórcios gigantes de TI de que precisamos agora tornarnos tecnologicamente mais inteligentes para salvar nossas cidades e considerar as consequências sociais mais tarde é altamente preventiva, para não mencionar, ideológica. Devemos ter cuidado com cenários inteligentes corporativamente inspirados, em que os problemas urbanos foram todos resolvidos pela tecnologia e todos os seus habitantes são felizes e prósperos; por mais tentadora que esta visão seja. Subjacente a esta ideia está uma noção mais manipuladora de que as cidades são apenas "máquinas para ganhar dinheiro" ou que a competitividade global entre as cidades irá tornálas automaticamente melhores lugares para viver (HOLLANDS, 2015, p. 73. Tradução dos autores).

Desta forma, é importante questionar quais mecanismos permitiram - ou melhor dito: ativamente promoveram - esse movimento das políticas de smart cities pelo mundo.

A mobilidade de políticas é regulada por aquilo que Urry (2000) e Cresswell (2006) chamam de "regimes de mobilidade", i.e. regimes regulatórios configurações complexas de poder, normas e regras -, que governam a maneira como indivíduos, coletivos e estados-nação gerenciam relações sociais não só em copresença, mas também à distância. Assentados em estruturas e redes sociomateriais, os regimes de mobilidade são responsáveis por restringir ou potencializar fluxos de pessoas, mercadorias, matérias-primas, capital, sinais, informações e, o que nos interessa em particular aqui, políticas de gestão de cidades que fazem parte de sistemas urbanos altamente interconectados.

A noção de mobilidade de políticas, por um lado, não nos deixa esquecer de que as políticas não se movem sozinhas, elas dependem de que pessoas e instituições as "movam": por canais virtuais, com reuniões por videochamada ou 
transferência de documentos e relatórios; ou por meio do deslocamento físico de governantes, policymakers, arquitetos, urbanistas, pesquisadores, empresários, lobistas, entre outros. Esse variado grupo de pessoas viaja para 'ver uma política in loco': conversas com dirigentes locais, visitas a lugares influenciados pela política em questão, desenvolvimento de acordos e parcerias, ou até mesmo a mera oportunidade de conhecer lugares com os quais se pode aprender novas soluções - é o que González (2011) chama de turismo de política urbana. No caso do Rio de Janeiro, documentos localizados por Freitas (2018) permitem estimar que mais de 10.000 pessoas (políticos, funcionários públicos, empresários, policy makers, pesquisadores, lobistas, etc.) visitaram o COR entre 2010 e 2016. Considerando que se trata de uma repartição pública, esse número é bastante expressivo.

As políticas transformam-se enquanto se movem e, quando aportam em um determinado espaço-tempo, já não são as mesmas. A mobilidade das políticas a que nos referimos aqui não conota apenas uma mudança de localidade, uma política viajando do ponto A para o ponto B. Dizer que as políticas são móveis não significa que elas estejam simplesmente viajando através de uma paisagem, é bem mais do que isso: elas estão refazendo as paisagens, material e simbolicamente (PECK; THEODORE, 2010). Dito de outro modo: as políticas em si são concebidas como uma rede que assume diferentes formas ao longo das linhas que elas constituem no momento mesmo em que as percorrem. A mobilidade de políticas segue, portanto, o modelo de espaço relacional, produzindo uma imagem de lugares interconectados enquanto depende dessa conexão para existir como tal (MASSEY, 2005). Como adverte Prince (2012), não se trata apenas de documentos viajando autonomamente por redes virtuais ou de diretrizes sendo aplicadas em contextos variados. Trata-se da reconstituição de campos de poder: ao se moverem, as políticas refazem as relações entre as localidades, reduzindo - para o bem ou para o mal - as fronteiras entre elas, costurando redes simbióticas e sistemas circulatórios, construindo comunidades supostamente cosmopolitas de "boas práticas" e validando conhecimentos de especialistas.

No caso específico da mobilidade de políticas de gestão urbana, vale recuperar o que diz Crivello: "os canais de circulação e reprodução de ideias urbanas aparentam ser múltiplos e hibridizados, incluindo, por exemplo, diferentes tipos de redes formais e informais, envolvendo prefeitos, gerentes urbanos e burocratas" (2015, p. 911. Tradução dos autores). Com sua análise sobre as ações de "regeneração urbana" de Puerto Madero, em Buenos Aires, Jajamovich (2016) nos ajuda a refletir sobre os papéis desempenhados por esses diferentes 
stakeholders ao diferenciá-los entre "ofertantes" e "demandantes" dessas políticas. As políticas circulam, pois há agentes interessados e que se beneficiam - em diferentes escalas - dessa circulação.

De que maneira o Rio de Janeiro passou a fazer parte dessa rede transnacional de "cidades inteligentes"? Como foi possível passar da figura de demandante dessas políticas tidas como bem-sucedidas alhures para a figura de ofertante de políticas? É dessas indagações que trata a próxima seção.

\section{Rio Smart City}

Em função da alta visibilidade dada à cidade do Rio de Janeiro no ciclo dos megaeventos, muitas empresas transnacionais passaram a pleitear parcerias com a Prefeitura do Rio. Uma dessas empresas foi a IBM, que, antes de direcionar seus esforços para o programa Watson ${ }^{69}$, liderou o mercado das smart cities. $\mathrm{O}$ flerte entre a gestão do prefeito Eduardo Paes e a IBM se intensificou em 2009, quando o Rio foi convidado a participar do Smarter Cities Challenge. Segundo documento institucional, a empresa fornece

às cidades de todo o mundo concessões de conhecimento e tecnologia IBM para enfrentar seus principais desafios estratégicos. As cidades vencedoras recebem uma equipe de especialistas da IBM em período integral por três semanas, com todos os custos assumidos pelo IBM Citizenship. As equipes aproveitam a computação cognitiva da IBM, a plataforma em nuvem, a análise móvel e social e os amplos recursos de dados climáticos para fornecer informações profundas e orientadas por dados que ajudam a melhorar o desenvolvimento de políticas e a tomada de decisões nas cidades..$^{70}$

A iniciativa ajudou a ampliar a capilaridade da IBM nessa rede transnacional e possibilitou que a empresa difundisse sua visão de smart city, fazendo circular uma narrativa corporativa bastante peculiar no mundo do planejamento urbano (SÖDERSTRÖM; PAASCHE; KLAUSER, 2014). Wiig (2015a) explora com rigor essas peculiaridades e sugere que, já no primeiro ano, a diretoria da IBM buscou

\footnotetext{
${ }^{69}$ Na década de 2000, a IBM buscou - e conseguiu por anos consecutivos - a liderança no mercado global das tecnologias para as smart cities. Na segunda metade da década de 2010, ela reajusta seus objetivos e passa a focar no Watson, uma plataforma de serviços cognitivos para negócios. Na nossa avaliação, não significa que a IBM tenha abandonado o mercado de smart cities, só que este não é mais o carro-chefe da empresa.
}

${ }^{70}$ Disponível em: http://www.smartercitieschallenge.org/ Acesso em: 05 set. 2020. 
os governantes de algumas cidades com as quais tinha bom relacionamento institucional para dar início ao programa. Por sua vez, os agentes públicos das cidades participantes estavam interessados não somente nas estratégias de gerenciamento "inteligente" e no seu potencial para melhorar as questões urbanas, como estabelecido pelo desafio. Mais que tudo, eles buscavam aprender como poderiam aproveitar essa "inteligência" para vender suas cidades como cidades globais. As que participaram do desafio puderam sustentar perante investidores internacionais uma imagem de "competitivas", "criativas" e de "governança estratégica eficiente". Nesse sentido, pôr em prática as estratégias propostas pela IBM para solucionar os problemas identificados por ela pareciam não estar necessariamente no topo da lista de prioridades dos governantes (WIIG, 2015a).

Nesse sentido, Wiig (2015b) sugere que a ideia de cidade inteligente funciona como uma máscara para as estratégias de governança empresarial. Em vez de melhorias especificamente voltadas para a cidade, as políticas propunham a mudança urbana por meio da ampliação do uso de ferramentas digitais. Supõese que o interesse das cidades em participar do desafio resida majoritariamente na exposição que ele proporciona, sinalizando aos investidores que a cidade está antenada com as ferramentas de governança inteligente. Em muitos casos, ser "inteligente" pode ser entendido como estar aberto ao capital estrangeiro. Com o Smarter Cities Challenge, a IBM emprestava seu prestígio às cidades, uma marca distintiva crucial para que as cidades sobressaiam neste mundo de economia globalizada.

O prêmio do "desafio" oferecido pela IBM consistia, em linhas gerais, em um trabalho de consultoria. No caso do Rio de Janeiro, foi sugerida aos gestores a criação do cargo de Diretor de Assuntos Digitais e da "Rio Negócios", agência de promoção de investimentos. Além disso, a participação no desafio contribuiu para o estreitamento dos laços entre a IBM e a prefeitura, o que foi crucial para a criação do Centro de Operações Rio. Paes, em entrevista concedida a Freitas (2018), dá alguns detalhes sobre essa negociação:

Nessa época, não me lembro exatamente o mês, o Rio tinha ganhado as Olimpíadas seis meses antes e você tinha uma coisa de grandes empresas indo ao Rio para começar a botar um pezinho lá. Aí foi o Sam Palmisano da IBM, pica das galáxias, tal. E eu estava de super mau humor no dia. O Sam Palmisano chegou lá no Palácio da Cidade para uma reunião comigo e começou a falar assim: "Eu quero doar uns computadores para as escolas do município". Eu estava no dia meio grosseiro, aí falei: "Desculpa, mas acho que o senhor errou de continente. Isso aqui não é África. A gente tem 
1700 escolas. Se o senhor for doar computadores para todas as escolas, eu até aceito, mas se for pra doar para vinte e depois você botar no seu livro de marketing social no fim do ano que você salvou as criancinhas pobres do Rio de Janeiro". Aqui pra você! Não preciso. Se você quer ajudar mesmo, eu estou pensando em fazer um negócio assim, assado..." aí contei um pouco do que eu imaginava para o Centro de Operações. Aí falei: "Bota seu time pra pensar isso comigo". Ele topou o desafio. (EDUARDO PAES, entrevista gravada por Freitas em 02 de outubro de 2017)

O relato do ex-prefeito corrobora o interesse bilateral na parceria: a Prefeitura queria utilizar a expertise da empresa estado-unidense para "aprimorar a gestão", enquanto a IBM poderia utilizar como vitrine para seus serviços uma cidade cuja imagem há muito circula em escala global e que estaria mais ainda em evidência por conta dos megaeventos. Durante a entrevista, o ex-prefeito foi questionado sobre o peso das Olimpíadas para o desenvolvimento do COR.

Eu diria que foi pequeno [o peso das Olimpíadas para a inauguração rápida do COR]. Eu inaugurei... Os olímpicos estavam aqui. Vamos dizer que já inauguramos alguma coisa das Olimpíadas? Sim, vamos lá. Nas Olimpíadas se previa que se teria um centro de controle olímpico. Mas não tinha previsão nenhuma de COR. Era um centro de operações que você faz em qualquer Olimpíada. Aproveitei, embalei aquilo ali e chamei Jaque Rogge pra inaugurar, mas não era uma coisa... No final, teve um momento ali no Rio que tudo que você fazia, mesmo que não fosse para a Olimpíada, diziam que você estava fazendo para as Olimpíadas. Explodia bueiro e diziam: "como que vai fazer a Olimpíada? E a Copa com esses bueiros explodindo?" Teve uma hora que eu percebi isso: aqui, agora tudo é Olimpíada, quer queira ou não. Você tinha uma mensagem muito forte e tudo virou Olimpíada. Mas não teve influência nenhuma de Olimpíada, não. A influência ali foi a lambança, a tragédia que aconteceu em 2010 (EDUARDO PAES, entrevista gravada por Freitas em 02 de outubro de 2017).

Como Paes afirma no trecho reproduzido, uma das exigências do COI foi que o Rio tivesse um centro de controle para a Olimpíada. Ainda que o COR possa não ter sido pensado com esse intuito, sua inauguração ficou marcada como a entrega da primeira obra do Rio Olímpico ${ }^{71}$. E, de certa maneira, os megaeventos

\footnotetext{
${ }^{71}$ No dia 31 de dezembro, houve uma cerimônia especial para a inauguração do COR, que contou com a presença de Gilbert Felli, diretor de Jogos Olímpicos do COI; Carlos Arthur Nuzman, presidente do Comitê Rio 2016 e ex-presidente do Comitê Olímpico Brasileiro (COB); Nawal El Moutawakel, presidente da Comissão de Coordenação dos Jogos Olímpicos Rio 2016; Jacques Rogge, presidente do Comitê Olímpico Internacional (COI), e Eduardo Paes, ex-prefeito do Rio de Janeiro.
} 
que ocorreram entre a inauguração e os Jogos Olímpicos serviram como oportunidades de teste e experimentação. Foi o caso do $5^{\circ}$ Jogos Mundiais Militares: mesmo sendo ainda muito recente, o COR teve participação importante no monitoramento do evento, ocasião em que a sala de controle carioca contou com a presença de três militares por turno, acompanhando as 450 câmeras de que o centro então dispunha.

Vale lembrar que, em paralelo ao COR, foi criado o Centro Integrado de Comando Controle (CICC-RJ), ao qual caberia exclusivamente o monitoramento e a gestão da segurança pública e do conflito urbano ${ }^{72}$. A simbiose entre o COR (gestão urbana) e o CICC (gestão da segurança) representa a consolidação de um novo modelo de controle de fixos e fluxos baseado tanto na integração e coordenação centralizada de atores heterogêneos quanto na capacidade de monitoramento e controle remoto de informações dispersas (HIRATA; CARDOSO, 2016; FIRMINO, 2017). Em ambos os casos, há um jogo complexo entre visibilidades e invisibilidades que, com base na observação participante realizada no COR por um de nós (FREITAS, 2018), abordamos a seguir.

\subsection{Centro de Operações Rio: (In)visibilidades e controle}

Inaugurado em 31 de dezembro de 2010, o Centro de Operações Rio consiste, principalmente, em uma grande sala de controle com amplo acesso a informações, providas por um complexo e moderno - para a época, pelo menos - sistema que integra centenas de câmeras espalhadas pela cidade. Em um único espaço, o COR centraliza os fluxos de dados de 30 agências públicas, incluindo tráfego e transporte público, serviços municipais e de utilidade pública, serviços de emergência, registros climáticos e informações enviadas pelos funcionários e pela população, por telefone, internet e rádio, possibilitando que a prefeitura consiga, em tese, dar uma resposta rápida e eficiente às situações de emergência (KITCHIN, 2014). Além da IBM, outras grandes empresas, como Cisco, Motorola e Samsung, também participaram de sua elaboração em algum nível.

Os "olímpicos", como Paes se referiu em entrevista, puderam acompanhar o funcionamento do COR na gestão da cidade durante a festa de Reveillón. Mais informações em: PREFEITURA do Rio de Janeiro. Prefeito e presidente do COI inauguram o Centro de Operações Rio. 31 de dezembro de 2010. Disponível em: http:/ / www.rio.rj.gov.br/web/guest/exibeconteudo?id=1423000 Acesso em: 08 jul. 2020.

72 Nas 12 cidades-sede da Copa do Mundo FIFA 2014, foram construídos centros de operações similares, tendo CICC do Rio como polo de coordenação regional, cabendo ao de Brasília a coordenação nacional. 
O uso de salas de controle para auxiliar a gestão urbana não constitui novidade: elas surgem com o processo de computadorização das indústrias na década de 1960 (IVERGÅRD; HUNT, 2009). Com um olhar menos rigoroso, poderíamos, inclusive, mencionar as salas de controle utilizadas para a coordenação do tráfego nas linhas férreas no início do século XX. O que chama a atenção no contexto contemporâneo é a concatenação das ferramentas de comunicação, vigilância e controle no desenvolvimento de políticas de smart cities.

No mezanino, voltado para a Sala de Controle, está localizada a Sala de Imprensa do COR. Profissionais dos principais veículos de comunicação têm um espaço de trabalho e conseguem transmitir em tempo real informações sobre o trânsito, meteorologia, ou qualquer outro acontecimento que se julga relevante para o dia a dia do cidadão carioca. Os profissionais da imprensa têm reservado um espaço que comporta 16 jornalistas trabalhando ao mesmo tempo, dispondo de computadores e telefones, além de um link - até então, usado majoritariamente pela Rede Globo - que possibilita que o repórter faça comunicados ao vivo para as edições do jornal local e, em casos extraordinários, para os telejornais de alcance nacional. Além disso, eles têm visão e audição plena de tudo o que está acontecendo na Sala de Controle. Uma das coisas que mais impressiona os visitantes é justamente o fato de a sala de imprensa poder acompanhar todo o funcionamento do Centro (cf. FREITAS, 2018, cap. 3).

Além da forte presença nas redes sociais, muito da projeção do COR se deve a esse trabalho colaborativo com a imprensa. Ter um jornalista à disposição dentro do COR possibilita que o veículo leve a seu espectador, ouvinte ou leitor, a informação em tempo recorde, além de ter a credibilidade de que tal informação vem de um órgão da Prefeitura do Rio. Em contrapartida, as informações que saem do COR para a mídia são, de certa forma, mediadas pela própria prefeitura. Em algumas situações mais críticas, logo após a veiculação de determinada notícia, um representante oficial concede uma entrevista ou emite um comunicado oficial sobre a ocorrência, as medidas tomadas e recomendações para a população. Em muitas ocasiões, quando os veículos de comunicação recebem mensagens sobre qualquer problema, eles repassam a um funcionário do Centro para que a informação seja apurada. Nessa configuração, a prefeitura consegue se posicionar imediatamente em relação às notícias. Paes reconhece o papel estratégico dessa parceria com a imprensa:

Talvez a jogada mais inteligente que eu tenha feito foi ali, na origem, também perceber a importância da imprensa para o COR. Porque era um pouco da minha experiência aqui, garoto novo, e minha experiência em 
2010 que eu não tinha um walkie-talkie, um radinho para falar com o povo. Eu fui para a Rádio Tupi, Rádio Globo, CBN, para as [rádios] FM para dizer: "olha, fica em casa". Então, na origem, eu liguei pra Band, pra Record, pra Globo, para o SBT, para dizer: "ó, estou montando isso e tal, entra aqui, faz isso - [inaudível]. A Globo foi a única que topou, chegou ao absurdo de ter uma câmera fixa ali. Você pode chegar ali e só ligar a câmera. Eu montei aquela sala de imprensa porque eu queria os caras ali. A imprensa é fundamental naquilo. Qual o custo da informação? A Globo vai e copia a gente. Você vê o Radar RJ, é uma cópia do COR. O Radar RJ reproduz o que o COR faz. Totalmente! Em um momento, nem davam o crédito devido: "Estamos aqui, o nosso radar está mostrando que o índice pluviométrico..." Tudo bem. Mas só todo dia de manhã ter uma imagem da prefeitura do Rio na TV... Eu usei muito a imprensa nisso, especialmente a Globo. Porque a Globo comprou a ideia (EDUARDO PAES, entrevista gravada por Freitas em 02 de outubro de 2017).

É preciso refletir também sobre como essas informações chegam até o espectador, ouvinte, leitor. Receber notícias de dentro de um órgão da prefeitura e ter um posicionamento oficial nos acontecimentos mais críticos da cidade transmite a ideia de onisciência da prefeitura. O COR estende a lógica da sala de controle para toda a cidade e, com sua superexposição, incorpora a população como um elemento funcional na gestão da cidade (LUQUE-AYALA; MARVIN, 2016).

Presente na televisão, rádios, redes sociais e aplicativos, o COR pretende ser, portanto, uma referência próxima e confiável no cotidiano dos cidadãos. Ao mesmo tempo que transmite a ideia de ampla transparência da gestão da cidade, o uso dessas tecnologias reforça a ilusão de total controle (LUQUE-AYALA; MARVIN, 2016). Nesse sentido, a criação do Centro de Operações Rio marca um ponto de inflexão na governança municipal do Rio de Janeiro em que a gestão tecnológica das redes de infraestrutura é valorizada e tornada visível. Se as redes de infraestrutura de uma cidade, por definição, costumam ser invisíveis quanto mais complexo e corriqueiro seu uso, mais difícil de se enxergá-lo (LUQUE-AYALA; MARVIN, 2016) - o COR utiliza sua visibilidade como uma ferramenta a seu favor. Os veículos de comunicação ajudam a construir o COR, no imaginário coletivo da cidade, como a principal ferramenta para a gestão de suas infraestruturas. Ao invés de ser invisível, o COR funciona não só como um centro de controle e monitoramento, mas também como um canal simbólico - e poderoso - de comunicação entre a prefeitura e a população. 


\subsection{Políticas de Mobilidade: Mobilidades urbanas e o cotidiano da cidade}

Mobilidade urbana compreende todas as mobilidades que se sucedem no espaço urbano, sejam elas corpóreas, de objetos materiais, comunicativas, virtuais e/ou imaginativas - para nos apropriarmos das categorias propostas por Urry (2007). As formas como as pessoas performam suas mobilidades diariamente dizem muito sobre a sociedade da qual fazem parte, revelando de maneira muito concreta dimensões das desigualdades sociais nem sempre perceptíveis em outros contextos de interação (JIRÓN; GOMEZ, 2018). “A mobilidade urbana é muito mais do que o transporte. (...) Uma grande parte do nosso dia a dia na cidade contemporânea ocorre em rotores e entre nós", resume Jensen (2009, p. 149. Tradução dos autores). Se as pesquisas que informam as políticas públicas tendem a ignorar o transporte como um ambiente de interação social, "como um novo domínio público que cria culturas de movimento" (ibid), não é de se estranhar que as intervenções limitem-se, não raro, à correção de aspectos técnicos, como o incremento da velocidade do trajeto, por exemplo.

A preparação da cidade do Rio de Janeiro para os megaeventos envolvia obras infraestruturais de mobilidade terrestre, como a expansão da linha 4 do Metrô, a construção das linhas dos BRTs Transolímpica, Transcarioca e Transoeste e o VLT (Veículo Leve sobre Trilhos) no Centro. Os gastos com a infraestrutura de transporte ultrapassaram R\$ 13 bilhões (SANTOS JUNIOR; NOVAES, 2015) e tinham como objetivo desenvolver um sistema que conectasse as áreas onde iriam acontecer as competições, sobretudo na região do bairro de Deodoro ${ }^{73}$.

Pereira et al. (2017) mediram a quantas escolas e oportunidades de trabalho as pessoas tinham acesso a partir de suas residências utilizando transporte público ou caminhando, em percursos de 60 minutos. Comparando dados de 2014 e 2017, seria possível avaliar o impacto das reformas em infraestrutura de transporte realizadas para as Olimpíadas. Ainda que o recorte temporal seja relativamente curto, a pesquisa revela como os investimentos trouxeram poucos benefícios para os mais pobres. Tomando como base dados do Censo, a pesquisa demonstra algo que, de certa forma, já era sabido: os grupos mais pobres estão localizados ao norte e nordeste da cidade, enquanto os mais ricos estão localizados ao sul, ao longo da costa, e no centro, onde ainda se concentra boa parte da atividade econômica. A criação da Linha 4 do metrô, que liga a Zona Sul à Barra da Tijuca,

\footnotetext{
${ }^{73}$ A escolha de Deodoro para ser um dos locais de competição - e as obras infraestruturais no sistema de trânsito - teria como objetivo beneficiar populações economicamente vulneráveis, que moram em regiões mais distantes do centro da cidade e que, geralmente, gastam mais tempo em seus deslocamentos (ver DAVIES, 2017).
} 
foi a obra de maior investimento e beneficiou, principalmente, os moradores dessas regiões.

Além de ser a cidade mais populosa do Estado, com cerca de 6,7 milhões de habitantes (IBGE, 2020), o Rio de Janeiro recebe, como se sabe, pessoas vindas de sua região metropolitana (RMRJ). Segundo Ferreira (2017), a partir de análise dos números do censo de 2010, mais de meio milhão de pessoas que residem em outros municípios trabalham na cidade do Rio, realizando esses deslocamentos pendulares diariamente. Segundo a Firjan, mais de 60\% dos fluxos na RMRJ têm como origem ou destino (ou ambos) a capital (FEDERAÇÃO DAS INDÚSTRIAS DO ESTADO DO RIO DE JANEIRO, 2014).

Encurralada pelo oceano e configurada por variados acidentes geográficos, como maciços, lagoas, serras, baías, a malha rodoviária do Rio de Janeiro tem uma série de gargalos e afunilamentos que limitam significativamente as opções de trajeto. Segundo dados do Sistema de Navegação TomTom (2019), em percursos de 30 minutos, foram gastos em média 172,2 horas a mais no trânsito ao longo de um ano. Assumindo que a jornada de trabalho é de oito horas, o número de horas gastas no trânsito equivaleria a 21,5 dias de trabalho. A Firjan (2014) chegou a uma estimativa do "custo da (i)mobilidade" na RMRJ e na Região Metropolitana de São Paulo. Em 2013, o custo dos congestionamentos chegou a R \$ 29 bilhões. Estimava-se que, com a conclusão das obras, esse custo cairia para R \$ 25 bilhões em 2014 e 2015; se não houvesse novos investimentos nos próximos anos, esses valores subiriam proporcionalmente ao aumento dos congestionamentos. As consequências dos congestionamentos não têm, obviamente, apenas caráter econômico, gerando também rebatimentos na qualidade de vida da população.

"O COR é considerado", destaca Rodrigo Firmino (2017, p. 25), “o estado-daarte em termos de centro de controle e gerenciamento de cidades, monitorando fixos e fluxos urbanos". De fato, além de servir como um quartel general para a gestão dos eventos extraordinários - como o caso dos megaeventos -, o COR teve e ainda tem um papel fundamental na gestão diária da mobilidade urbana no Rio de Janeiro. 
Figura 1 - Sala de Situação - Centro de Operações Rio

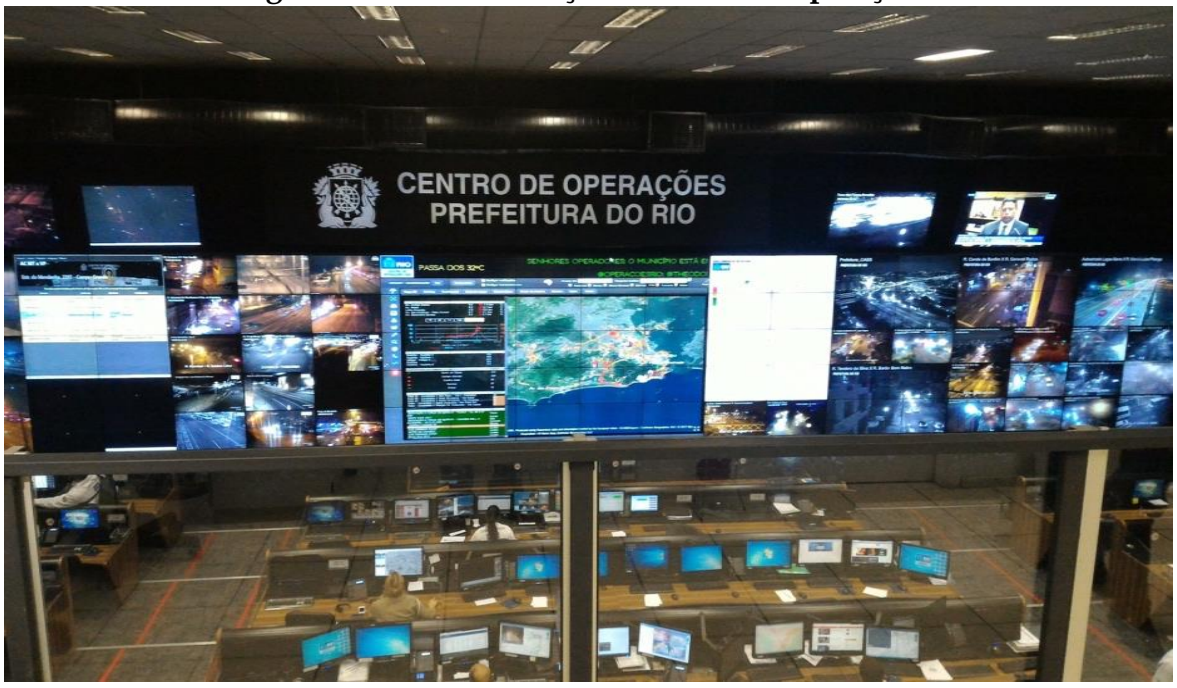

Fonte: Acervo de Freitas (2018).

É nesse contexto que o COR assume papel importante no cotidiano da cidade, aplicando as ditas tecnologias inteligentes na gestão das mobilidades urbanas. As mais de mil câmeras, das quais agora o COR dispõe, monitoram as principais vias da cidade. Em questão de segundos, é possível visualizar na Sala de Situação qualquer incidente que, eventualmente, esteja atrapalhando as mobilidades urbanas e, a partir disso, acionar os órgãos que poderão ajudar na solução, seja a Guarda Municipal, a Polícia Militar, a Defesa Civil, ou qualquer outro que tenha representantes na sala de controle da Prefeitura do Rio.

No Rio de Janeiro, as rádios locais costumam transmitir detalhes sobre a situação do trânsito, principalmente pela manhã, quando a maioria das pessoas está indo para o trabalho, e no final da tarde, quando costumam retornar para suas casas. Antes a forma mais eficiente para cobrir as principais vias da cidade era o chamado "repórter aéreo": sobrevoando a cidade em um helicóptero, o repórter informa aos espectadores as condições do trânsito. Em uma das visitas ao COR, Freitas (2018) presenciou a repórter de uma rádio passar informações sobre o trânsito, diretamente do mezanino.

Desde 2013, o sistema do COR é alimentado também pelos dados do aplicativo de navegação do Waze e pelas informações do aplicativo para usuários de transporte público Moovit. Esses dados agregados possibilitam que os operadores tenham feedback em tempo real sobre tempos de deslocamento, problemas operacionais nos meios de transporte público, além de intempéries 
nas vias, como buracos e alagamentos. Em troca de compartilhar dados do seu sistema com a prefeitura, o Google - atual dono do Waze - também recebe informações enviadas pelo COR, em relação a interdições, obras planejadas e radares de trânsito, por exemplo.

A primeira parceria do Waze foi com o Centro de Operações do Rio, com o COR. Eu lembro que na época o pessoal dizia: "Vamos desenvolver aqui uma tecnologia..."Que desenvolver tecnologia, caramba? Tem um aplicativo aqui que você baixa de graça". Você bota aí no telão, malandro. A população está te informando. A verdade é essa. No começo não era assim. A tecnologia avançou muito se comparada a sete anos atrás. Hoje, com esses aplicativos todos é uma loucura. O Waze foi até uma ideia minha mesmo, cheguei assim para o Pedro e falei: "Pedro, pelo amor de Deus!" O pessoal estava querendo desenvolver um aplicativo. "Vai na porcaria do Waze, vamos fazer contato". (EDUARDO PAES, entrevista gravada por Freitas em 02 de outubro de 2017)

Tão importante quanto ter as informações do trânsito é fazê-las chegar ao cidadão. A ideia do Rio de Janeiro como cidade inteligente passa diretamente por esse sistema de transmissão de dados. A máxima de que uma cidade inteligente é aquela em que os seus cidadãos são inteligentes ganha contornos interessantes se confrontada com caso em tela, sobretudo se considerarmos inteligência a habilidade de se adquirir, entender e usar a informação. As pessoas que vivem não só as que moram, mas também as que trabalham, estudam ou circulam - no Rio utilizam as informações que o COR divulga para tomar decisões, seja em relação ao trânsito, às condições climáticas ou até mesmo ao risco que moradores de algumas áreas correm durante fortes chuvas.

As redes sociais têm papel fundamental nessa comunicação direta com o cidadão, e o COR mantém vários perfis. Por conta das características diferentes das próprias redes, as postagens seguem padrões diferentes: no Instagram, geralmente, trazem paisagens da cidade, imagens das câmeras a que o Centro tem acesso e imagens com algum aviso. Os tweets (postagens no Twitter) são muito mais frequentes, em torno de quatro ou cinco a cada hora, e em situações críticas o número de postagens aumenta exponencialmente. As postagens do Facebook repetem muitas das imagens utilizadas no Instagram, além de divulgar os três boletins diários (6h, 11h e 18h) em texto e em vídeo. Além disso, desde 2017, um bot (software que simula ações humanas) envia mensagens diretas a todos os usuários que interagiram com o perfil do COR no Facebook.

Além disso, os painéis e relógios espalhados pela cidade - que mesmo antes da existência do COR já exibiam informativos - são agora alimentados com as 
informações sobre o tempo de percurso das vias, possibilitando que os motoristas saibam qual o melhor trajeto a ser percorrido.

Gestão de cidade, gestão de coletividade, com componentes de risco, de emergência e com as novas formas de você ver uma cidade resiliente, sem comunicação não existe. Porque se você considerar resiliência sua capacidade de suportar o choque, você até tomba, mas você levanta de volta. Se você considerar a resiliência da cidade como uma capacidade de uma cidade viver problemas, sofrer pressões de ameaças naturais, sociais, econômicas, e se reestabelecer. Uma parte importante dessa condição é que você se comunique, porque em alguns momentos seu recurso é muito inferior à pressão que você está tomando. Então quando começa uma chuva forte, por exemplo, não tem trator, ou bomba d'água ou o caramba que vá fazer parar de chover ou impedir de uma rua alagar. Em certos momentos, é uma questão física mesmo, então a gente não vai conseguir ir contra isso. Então, nesses momentos, o principal recurso é a comunicação, porque você compartilha, você empodera quem está te ouvindo, com quem você está falando, né? Tem a comunicação operacional e tem a comunicação de alerta, podem ser as duas, mas a gente está falando mais daquela de entrevista mesmo, que é mais mão-única. Nesse momento, eu estou empoderando a população da cidade a decidir melhor e se cuidarem. (EX-CHEFE EXECUTIVO DO COR, entrevista para Freitas)

Outros entrevistados também concordavam que a informação gerada ali precisa sim ser divulgada pelos veículos de comunicação, e a transparência deve ser um dos principais valores a reger o Centro. No que diz respeito à mobilidade urbana, sobretudo, as informações do COR só passam a ser relevantes à medida que são reverberadas e impactam as decisões e ações da população, por exemplo, optando por um trajeto em detrimento de um outro mais congestionado.

A visibilidade do Centro e a divulgação pela mídia dos seus dados fizeram com que o COR assumisse um papel diante da população que descolou o caráter funcional de sua imagem simbólica: o COR deixa de ser um instrumento de "governança inteligente" e passa a ser também encarado como o representante tecnológico do controle da Prefeitura sobre a cidade e sobre a experiência urbana de sua população. Essa ampliação tanto técnica quanto simbólica das funções do Centro de Operações Rio demonstra o transbordamento da tecnologia para novas atividades e a criação de lógicas próprias de atuação que constituem as novas formas de mobilidades em disputa no Rio de Janeiro, nas quais o COR é instrumento fundamental.

Na década de 1990, quando a internet estava deixando de ser utilizada apenas para fins acadêmicos e se tornando comercial, Mitchell (1996) já destacava as 
grandes transformações por que passariam as cidades a partir do desenvolvimento de tecnologias que intersectavam o físico, o virtual e o portátil. A partir dos anos 2000, a internet de alta velocidade se popularizou e as chamadas "mobilidades miniaturizadas" (ELLIOTT; URRY, 2010) - tais como os celulares e outros dispositivos móveis - passaram a exercer papel fundamental na maneira como as pessoas performam suas vidas em trânsito.

O sistema do COR tem uma interface de integração com Waze, Moovit e Google Maps. Esses aplicativos obtêm informações de satélites e GPS para avaliar em tempo real a situação do trânsito na cidade. Adey e Bevan (2006) trabalham com o conceito de cybermobilities para explicar como, com o uso ostensivo da tecnologia, as mobilidades físicas e virtuais estão cada vez mais imbricadas. A mobilidade física do carro e seu motorista é facilitada pela mobilidade virtual da informação. O componente virtual da cibermobilidade, neste mesmo exemplo, é gerado a partir do movimento físico (ou da inércia) dos outros carros. O conceito reforça como essas duas dimensões da mobilidade são mutuamente dependentes e necessárias: "As cibermobilidades são a combinação de movimentos virtuais e físicos, que são produzidos simbioticamente e mediados um pelo outro" (ADEY; BEVAN, 2006. p. 48. Tradução dos autores). A "coreografia no tempo-espaço" não está mais limitada aos espaços urbanos necessariamente físicos, mas também engloba o uso de uma multiplicidade de redes e espaços eletrônicos e digitais, à medida que os dispositivos móveis são usados como mediadores do cotidiano, e os próprios meios de comunicação começam a assumir a forma de redes eletrônicas globais. (GRAHAM; MARVIN, 2002).

Porém, mais uma vez, é importante trazer à luz que a mobilidade é um capital - por definição, distribuído de maneira desigual - em que não só a velocidade importa, mas também a praticidade e flexibilidade de que o sujeito dispõe para escolher rotas e gerenciar mobilidades de acordo com sua agenda (KAUFMANN; BERGMAN; JOYE, 2004). Ao tratar de cibermobilidades, a analogia com o capital se reforça, já que as dimensões física, virtual e comunicativa da mobilidade também não se distribuem de maneira equilibrada. Há décadas, o Rio de Janeiro enfrenta graves problemas de congestionamento e, mesmo com todos os investimentos feitos em infraestrutura por conta da Copa do Mundo e das Olimpíadas, a mobilidade urbana continua sendo um problema (BIENENSTEIN; MASCARENHAS, 2017; MACHADO; ARAGÃO PEDROSO; NASCIMENTO, 2018) 


\section{Considerações Finais}

Menos do que responder - afirmativa ou negativamente - à indagação que intitula este artigo, cabe pensar a quem interessa o Rio de Janeiro circular em nível global como uma "cidade inteligente" e que mecanismos de poder garantem a mobilidade dessa política de gestão urbana.

Mesmo que, convencidos pelo discurso institucional e empresarial, assumíssemos que a implementação das novas TICs na gestão do Rio de Janeiro a transformam numa cidade inteligente, seria preciso questionar se os conclamados benefícios dessa inteligência se distribuem de forma equânime por todo tecido urbano. Excetuando algumas cidades inteligentes built from scratch (GREENFIELD, 2013; KUECKER, 2015), como a coreana Songdo, os demais projetos de smart city dizem respeito somente a uma determinada região das cidades. Fala-se em cidade inteligente, no mais das vezes, metonimicamente, tomando uma parte como um todo. No caso do Rio de Janeiro, cujo projeto é centrado em uma sala de controle, como vimos aqui, a maior parte das câmeras monitoradas estão localizadas na Zona Sul e no Centro. Se há mais "olhos" voltados para determinada região, fica explícito que essa inteligência tem CEP.

Ao atuar fortemente na fronteira entre as mobilidades físicas, virtuais e comunicacionais, o Centro de Operação do Rio de Janeiro, como buscamos demonstrar, é um exemplo de como essas mobilidades se imbricam e, ao fazê-lo, não apenas reforçam assimetrias históricas, como criam novas desigualdades. A própria configuração do sistema de mobilidade urbana faz com que as informações repassadas pelo COR tendam a privilegiar os indivíduos que utilizam transporte particular - se estes podem utilizar rotas alternativas para chegar aos seus destinos, aos usuários do sistema de transporte público restam poucas opções, ficando, em geral, mais vulneráveis aos congestionamentos.

Ainda que o COR não tenha sido criado em função das Olimpíadas, como um dos trechos da entrevista de Paes atesta, parece-nos pertinente afirmar, por tudo o que foi discutido, que as ações e narrativas voltadas para o que aqui chamamos de projeto Rio Smart City colaboraram para dar credibilidade global àquela que se pretendia cidade-sede dos megaeventos. O apelido de Rio Olímpico, que a gestão de Paes e seus colaboradores do mundo corporativo tanto se esforçaram para emplacar, tomou emprestado da narrativa de cidade inteligente predicados como "racional", "preparada", "monitorada" e "previsível".

O Centro de Operações Rio ter recebido, no período entre 2011 e 2016, cerca de 10.000 visitantes é um indicativo de que o modelo de smart city instalado na capital fluminense servirá ou serviu, em diferentes escalas, de inspiração para 
projetos em outras cidades. Pela lente de Jajamovich (2016), identificamos, portanto, uma mudança de papel da cidade do Rio de Janeiro nessa rede transnacional de circulação de políticas de cidades inteligentes. Em um primeiro momento, a cidade era uma "demandante": implementando pacotes de tecnologia da IBM, buscando legitimação junto a investidores, pleiteando premiações internacionais, alardeando os predicados associados ao dito urbanismo inteligente. Em um segundo momento, a cidade passa a ser uma "ofertante". Os megaeventos, como já se esperava, atraíram atenção internacional, e o próprio COR passou a servir como um lounge high-tech para receber as autoridades de outras cidades e países, como registrado por Freitas (2018). Se o Rio Olímpico se beneficiou da Cidade Inteligente Rio, como argumentamos, é também o relativo sucesso na organização dos megaeventos que legitimam a política de cidade inteligente como um modelo bem-sucedido, tornando-o apto a circular e assumir novas formas.

É possível especular que as políticas de cidades inteligentes seguirão se movendo, reposicionando-se muitas vezes de forma errática, ao sabor dos ventos políticos, dos humores e do implicit bias dos envolvidos - como a fala de Eduardo Paes demarca de maneira tão evidente. Se as políticas se transformam no processo de difusão, acompanhar os caminhos que elas percorrem exige um esforço de pesquisa contínuo e sensibilidade para capturar os aspectos efêmero e experimental de seus fluxos. À medida que mais agentes públicos e privados almejam que suas cidades sejam inteligentes - ou pelo menos não pareçam "burras" -, precisamos afiar a crítica para que a ideia de smart city, que já se presta a um sem-número de definições conflitantes (WIIG, 2015b), não seja celebrada como solução para problemas estruturais que demandam transformações pouco sensíveis a novos algoritmos e codificações digitais.

\section{Referências}

ADEY, Peter.

(2010). Aerial Life: Spaces, Mobilities, Affects.

0xford, Wiley-Blackwell.

ADEY, Peter; BEVAN, Paul.

(2006). Between the physical and the virtual: Connected mobilities. In: SHELLER, Mimi; URRY, John (eds.). Mobile Technologies of the City. London, Routledge, p. 44-60.
BIENENSTEIN, Glauco; MASCARENHAS, Gilmar.

(2017). Depois do Espetáculo: percepções e avaliações dos megaeventos esportivos no Rio de Janeiro. Anais ENANPUR. v. 17, n. 1, 2017.

BÜSCHER, Monika; URRY, John.

(2009). Mobile Methods and the Empirical. European Journal of Social Theory. vol. 12, n. 1, p. 99-116. 
CARAGLIU, Andrea; DEL B0, Chiara; NIJKAMP, Peter.

(2009). Smart cities in Europe. Serie Research Memoranda (VU University Amsterdam, Faculty of Economics, Business Administration and Econometrics).

CARVALHO, Luis.

(2015). Smart cities from scratch? A sociotechnical perspective. Cambridge Journal of Regions, Economy and Society. vol. 8, n.1, p. 4360.

CRESSWELL, Tim.

(2006). On the move: mobility in the modern Western World. New York, Routledge.

CRIVELLO, Silvia.

(2015). Urban policy mobilities: the case of Turin as a smart city. European Planning Studies. vol. 23, n. 5, p. 909-921.

DAMERI, Renata Paola.

(2013). Searching for smart city definition: a comprehensive proposal. International Journal of Computers \& Technology. vol. 11, n. 5, p. 2544-2551.

DAVIES, Frank.

(2017). Deodoro: formas de governo para uma "região olímpica". 199f. Tese (Doutorado em Ciências Sociais), Universidade do Estado do Rio de Janeiro, Rio de Janeiro.

ELLIOT, Anthony; URRY, John.

(2010). Mobile Lives. Oxford, Routledge.

FERREIRA, Ulisses.

(2017). Movimento Pendular, principais destinos e tempo de deslocamento para o trabalho na Região Metropolitana do Rio de Janeiro. XVII Enanpur. São Paulo.

FEDERAÇÃO DAS INDÚSTRIAS DO ESTADO DO RIO DE JANEIRO.

(2014) Os custos da (i)mobilidade nas regiões metropolitanas do Rio de Janeiro e São Paulo. Nota técnica n. 3. Rio de Janeiro.

FIRMIN0, Rodrigo José.

(2017). Securitização, Vigilância e Territorialização em Espaços Públicos na Cidade Neoliberal. Risco: Revista de Pesquisa em
Arquitetura e Urbanismo(on line). n.15, p. 2335.

FREITAS, João.

(2018). A invenção da Cidade Inteligente Rio: uma análise do Centro de Operações Rio pela lente das mobilidades (2010-2016). Tese de Doutorado. Rio de Janeiro: CPDOC/FGV.

GONZÁLEZ, Sara.

(2011). Bilbao and Barcelona 'in motion'. How urban regeneration 'models' travel and mutate in the global flows of policy tourism. Urban Studies. vol. 48, n. 7, p. 1397-1418.

GRAHAM, Stephen; MARVIN, Simon.

(2002). Telecommunications and the city. Electronic spaces, urban places. London e New York, Routledge.

GREENFIELD, Adam.

(2013). Against the Smart City (The City is Here for You to Use). New York, Do Projects.

HIRATA, Daniel; CARDOS0, Bruno.

(2016). Coordenação como tecnologia de governo. Horizontes antropológicos. vol. 46, p. 97-130.

HOLLANDS, Robert.

(2008). Will the real smart city please stand up? City. vol.12, p. 303-320.

HOLLANDS, Robert.

(2015). Critical interventions into the corporate smart city. Cambridge Journal of Regions, Economy and Society. vol. 8, n. 1, p. 61-77.

IBGE,

(2020). Estimativas da população residente com data de referência $1^{\circ}$ de julho de 2020. Diretoria de Pesquisas, Coordenação de População e Indicadores Sociais.

IVERGÅRD, Toni; Hunt, Brian.

(2009). Work in Control Room. In IVERGÅRD, T.;

HUNT, B. Handbook of Control Room Design and Ergonomics: A Perspective for the future. $2^{\mathrm{a}}$ ed. Boca Raton, CRC Press - Taylor \& Francis Group. p. 3-9. 
JAJAMOVICH, Guillermo Paz

(2016). Miradas relacionales sobre la circulación de políticas urbanas: la Corporación Antiguo Puerto Madero y el proyecto 'Mendoza Madero' (2003-2009), Journal of Latin American Geography. vol. 15, n. 3, p. 67-85.

JENSEN, Ole B.

(2009). Flows of Meaning, Cultures of Movements - Urban Mobility as Meaningful Everyday Life Practice. Mobilities. vol.4, n. 1, p. 139-158.

JIRÓN, Paola; GÓMEZ, Javiera.

(2018). Interdependência, cuidado e gênero: estratégias de mobilidade na cidade de Santiago. Tempo Social. vol. 30, n. 2, p. 55-72. https://doi.org/10.11606/01032070.ts.2018.142245

KAIKA, Maria; SWYNGEDOUW, Erik.

(2000). Fetishizing the modern city: the phantasmagoria of urban technological networks. International Journal of Urban and Regional Research. vol. 24, n. 1, p. 120-138.

KAUFMANN, Vincent; BERGMAN, Manfred; JOYE, Dominique.

(2004). Motility: mobility as capital. International Journal of Urban and Regional Research, 28, p. 745-756.

KITCHIN, Rob.

(2014). The data revolution: Big data, open data, data infrastructures and their consequences. London: Sage.

KUECKER, Glen David.

(2015). New Songdo City: a case study in complexity thinking and ubiquitous urban design. Conference Proceedings of the13th AESOP Planning and Complexity Thematic Group Meeting. Tampere, Finland: Ed. Jenni Partanen.

LIRA, Thiago $E$.

(2010). A paixão nos une? A identidade brasileira e a estratégia da candidatura do Rio de Janeiro aos Jogos Olímpicos de 2016. Revista de Estudos Internacionais. vol. 1, n. 1, p. 112-127.

LUQUE-AYALA, Andres; MARVIN, Simon

(2016). The maintenance of urban circulation: An operational logic of infrastructural control.
Environment and Planning D: Society and Space. vol. 34, n. 2, p. 191-208.

MACHADO, Marília; ARAGÃO PEDROSO, Luiz; NASCIMENTO, Denise

(2018). Os Jogos Olímpicos de 2016 e seu legado de mobilidade urbana para a cidade do Rio de Janeiro. Linkscienceplace-Interdisciplinary

Scientific Journal. vol. 5, n. 2.

MAHIZHNAN, Arun.

(1999). Smart cities: The singapore case. Cities. vol. 16, n. 1, p. 13-18.

MANDERSCHEID, Katharina.

(2009). Unequal mobilities. In OHNMACHT, Timo; MAKSIM, Hanja; BERGMAN, Manfred. Mobilities and inequality. Ashgate Publishing, p. 27-50.

MASCARENHAS, Fernando; ATHAYDE, Pedro Fernando Avalone; SANTOS, Mariângela Ribeiro dos; MIRANDA, Natália Nascimento.

(2012). 0 bloco olímpico: Estado, organização esportiva e mercado na configuração da agenda Rio 2016. The Journal of the Latin American Socio-cultural Studies of Sport (ALESDE). vol. 2, n. 2.

MASCARENHAS, Gilmar.

(2014) Natureza e tensões do urbanismo olímpico contemporâneo. In: OLIVEIRA, F. et al. (Org.). Geografia urbana: ciência e ação política. Rio de Janeiro: Consequência.

MASSEY, Doreen.

(2005). For Space. London: Sage.

MITCHELL, William.

(1996). City of Bits: Space, Place and Infobahn. Boston, MA: MIT Press.

NAM, Taewoo; PARD0, Theresa. A.

(2011). Conceptualizing smart city with dimensions of technology, people, and institutions. Proceedings of the 12th annual international digital government research conference: digital government innovation in challenging times. ACM, p. 282-291.

PECK, Jamie; THEODORE, Nik.

(2010). Mobilizing policy: Models, methods, and mutations. Geoforum. vol. 41, n. 2, p. 169-174. 
PEREIRA, Rafael H.; BANISTER, D.; SCHWANEN, T.; WESSEL, N.

(2017. Versão Preliminar). Distributional Effects Of Transport Policies On Inequalities In Access to Opportunities In Rio de Janeiro. SocArXiv.

PRINCE, Russell.

(2012). Metaphors of policy mobility: fluid spaces of "creativity" policy. Geografiska annaler: series $B$, human geography. vol. 94, n. 4, p. 317-331.

RANGEL, $\mathrm{S}$.

(2007, junho 23). Eterna candidata. Folha de São Paulo. Disponivel em: https://www1.folha.uol.com.br/fsp/especial/fj 2306200707.htm Acesso em: 26/06/2020

RAEDER, Savio.

(2010). Rio 2016 e o urbanismo olímpico. Biblio 3W. Revista Bibliográfica de Geografía y Ciencias Sociales, Universidad de Barcelona, Vol. XV, n० 895 (15).

ROCHA, Lia de Mattos.

(2018) Democracia e militarização no Rio de Janeiro: "pacificação", intervenção e seus efeitos sobre o espaço público. In: Márcia Leite; Lia Rocha; Juliana Farias; Monique Carvalho. (Org.). Militarização no Rio de Janeiro: da pacificação à intervenção. 1ed.Rio de Janeiro: Mórula Editorial. v. 1, p. 223-239.

SÖDERSTRÖM， Ola; PAASCHE， Till; KLAUSER, Francisco.

(2014). Smart cities as corporate storytelling. City. vol. 18, n. 3, p. 307-320.

SANTOS JUNIOR, Orlando; NOVAES, Pedro.

(2015). 0 Projeto Olímpico da Cidade do Rio de Janeiro: investimentos públicos e participação do setor privado. In CASTRO, D. G.; GAFFNEY, C.; NOVAES P. R. ; RODRIGUES, J.; SANTOS, C. P; Santos Junior, 0. A. Rio de Janeiro: os impactos da Copa do Mundo 2014 e das Olimpíadas 2016. Rio de Janeiro: Letra Capital.
SHELLER, Mimi.

(2018). Mobility justice: The politics of movement in an age of extremes. Londres/Nova Iorque: Verso Books.

SHELLER, Mimi; URRY, John.

(2006). The new mobilities paradigm. Environment and planning $A$. vol. 38, n. 2, p. 207-226.

SHELLER, Mimi; URRY, John.

(2016). Mobilizing the new mobilities paradigm. Applied Mobilities. vol. 1, n. 1, p.10-25.

URRY, John.

(2000). Sociology beyond societies. Londres/Nova York: Routledge.

URRY, John.

(2007). Mobilities. London: Polity.

VIDYASEKAR, A. D.

(2013. Disponivel em:

http://www.frost.com/sublib/display-

report.do?id=M920-01-00-00-00). Strategic opportunity analysis of the global smart city market: Smart city market is likely to be worth a cumulative $\$ 1.565$ trillion by 2020 . USA: Frost \& Sullivan.

WIIG, Allan.

(2015a). IBM's smart city as techno-utopian policy mobility. City. vol. 19, n. 2-3, p. 258-273.

WIIG, Allan.

(2015b). The empty rhetoric of the smart city: from digital inclusion to economic promotion in Philadelphia. Urban Geography, p. 1-19.

\section{Recebido em}

novembro de 2019

\section{Aprovado em}

julho de 2020 